\title{
Preparation of Ultrafine Magnesium Hydroxide with Two Kinds of Dispersing Agent
}

\author{
$\mathrm{Na} \mathrm{Hu}$ \\ College of Material Science and Engineering \\ Central South University of Forestry and Technology \\ Hunan, P.R. China \\ 505651234@qq.com
}

\author{
Zhi Ping $\mathrm{Wu}^{*}$ \\ College of Material Science and Engineering \\ Central South University of Forestry and Technology \\ Hunan, P.R. China \\ Wuzhiping02@163.com
}

\author{
Gui Wu Wang \\ College of Material Science and \\ Engineering \\ Central South University of Forestry \\ and Technology \\ Hunan, P.R. China \\ Wgwsuper21@sina.com
}

\author{
Peng Wen \\ College of Material Science and \\ Engineering \\ Central South University of Forestry \\ and Technology \\ Hunan, P.R. China
}

\author{
Wei Qian \\ College of Material Science and \\ Engineering \\ Central South University of Forestry \\ and Technology \\ Hunan, P.R. China
}

\begin{abstract}
In this study, Super fine magnesium hydroxide was synthesized by direct precipitation method. The influence of factors, such as reaction time, reaction temperature, solution concentration and the additive amount of dispersing agent on the particle size of MH were investigated. The properties of prepared $\mathrm{Mg}(\mathrm{OH})_{2}$ were studied by Laser particle size analyzer, X-ray diffraction(XRD). The results of XRD showed that the prepared $\mathrm{Mg}(\mathrm{OH})_{2}$ with two kinds of dispersing agent has the same structure compared to the typical $\mathrm{Mg}(\mathrm{OH})_{2}$. The average particle size is about $200 \mathrm{~nm}$. The study indicated that the ethanol and PEG6000 as the dispersing agent can obviously reduce the average size of samples by preventing particles reunion. From the point of view of economic and environmental protection, PEG6000 is better to used as the dispersing agents for preparating super fine magnesium hydroxide.
\end{abstract}

Keywords- Direct precipitation method; $\mathrm{Mg}(\mathrm{OH})_{2}$; ethanol; PEG6000

\section{INTRODUCTION}

Super fine magnesium hydroxide $(\mathrm{MH})$ has been used in polymer materials as a high performance inorganic flame retardants owing to its non-toxic, smoke suppression, highly decomposition temperature characteristics. It has become the hot spot of the research and development at home and abroad in recent years [1-5].

At present the preparation of ultrafine magnesium hydroxide includes a variety of methods, such as physical crushing method[6] 、 hydrothermal method[7-8] 、 homogeneous precipitation method[9] 、 direct precipitation method[10]. Physical crushing method has low efficiency due to its large energy consumption, highly impurity content and widely particle size distribution characteristics. Hydrothermal method go against industrialized production mode owing to need high temperature and high pressure equipment.

This work was financially supported by the cooperation project in industry, education and research of Guangdong Province and Ministry of Education of P. R. China (No. 2011B090400333 ), the research learning and innovative experiment of Hunan provincial undergraduate (No.2011148).
Homogeneous precipitation method can synthesize the smaller particles, but its reaction time is longer and production cost is higher than other methods. Generally speaking, direct precipitation method is widely used to synthesize super fine magnesium hydroxide owing to its simple operation process and lower production cost. And it usually synthesizes flake, needle and sphere of super fine magnesium hydroxide powder with soluble magnesium salt and different kinds of precipitation agent by controlling reaction conditions. However, the local high concentration of the precipitation agent will be appeared when it scatter unevenly by directly adding to the magnesium salts solution, which lead to the wide distribution of particle size. And the particle size is also related to the reaction time, reaction temperature and so on.

In this paper, the preparation of super fine magnesium hydroxide $(\mathrm{MH})$ by direct precipitation method was studied, the influence of reaction temperature, reaction time, solution concentration and two kinds of dispersant concentration on the particle size of super fine magnesium hydroxide $(\mathrm{MH})$ were investigated. The prepared products were characterized by Laser particle size analyzer and XRD.

\section{EXPERIMENTAL}

$\mathrm{Mg}\left(\mathrm{NO}_{3}\right)_{2} \cdot 6 \mathrm{H}_{2} \mathrm{O}$ and PEG6000 (or ethanol ) were charged into a closed round bottom flasks and stirred to homogeneous phase, then $10 \mathrm{~mL}$ of ammonia solution (25\%) was added dropwise to the above mixture and stirred for a few hours at different temperature. All of the resulting white precipitates were filtered, then washed with distilled water and absolute alcohol, and finally dried at $100^{\circ} \mathrm{C}$ to constant mass under vacuum conditions.

All samples were identified by the Laser particle size analyzer (MALV Mastersizer 2000), the average of three test results. X-ray powder diffraction ( XD-3, Beijing puxi general 
apparatus Co.), with $\mathrm{Cu}$ target at a scanning rate of $4^{\circ} \cdot \mathrm{min}^{-1}$ ranging from $10^{\circ}-70^{\circ}$.

\section{RESULTS AND DISCUSSION}

\section{A. reaction temperature}

The influence of reaction temperature on the particle size of magnesium hydroxide was presented in Fig.1. it implied the size of particles decrease firstly and then increase when the reaction temperature varied from $20{ }^{\circ} \mathrm{C}$ to $50^{\circ} \mathrm{C}$, which can be explained that the $\mathrm{MH}$ will distributes unevenly and keep amorphous state, which make themselves reunite into big particles when the synthetic reaction proceeds at low temperatures, With the rise of temperature, the solution viscosity reduce and solution molecular kinetic energy increase, the number of crystal cores formed increased quickly, which restrain the crystal growth quickly, so the particle size decreased. However, the crystal growth speed accelerate when temperature reach certain temperature (more than $45{ }^{\circ} \mathrm{C}$ ), the size of $\mathrm{MH}$ particle also increase obviously. At the same time, a few of ammonia will volatile at high temperatures, which cause the waste of resources and air pollution.

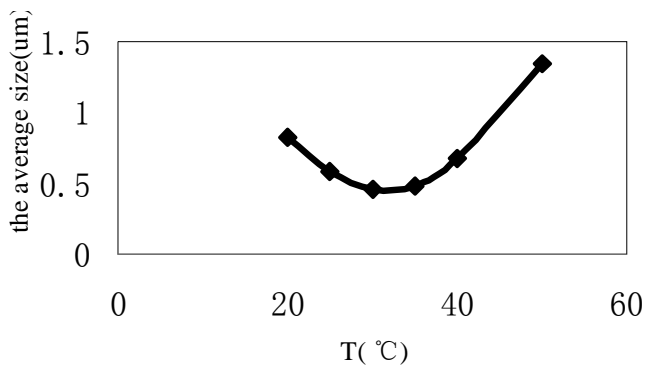

Fig.1.The influence of reaction temperature on $\mathrm{MH}$ average particle size

\section{B. Solution concentration}

The influence of solution concentration on the particle size of magnesium hydroxide was presented in Fig.2. With the increase of molar concentration of magnesium nitrate, the average sizes of Magnesium hydroxide increased obviously. However, when the solution concentration is $0.05 \mathrm{~mol} \cdot \mathrm{L}^{-1}$, the too low concentration make the saturation become small in the system, which is not benefit to generate a mass of crystal nucleus, the particle size of $\mathrm{MH}$ become big compared to 0.1 $\mathrm{mol} \cdot \mathrm{L}^{-1}$ solution concentration. When the crystal growth speed and the crystal nucleation speed keep in equilibrium state, it is benefit to product more stable and smaller super fine magnesium hydroxide $(\mathrm{MH})$. With the increase of the solution concentration, the solution saturation increases, and the crystal nucleation speed is faster than the crystal growth speed, which generate so much crystal nucleus that cause powder particle size distributing unevenly and make themselves reunite into big particles. On the other hand, with increasing of the proportion of ammonia, the products can completely precipitate. Figure 2 indicate that the solution concentration for $0.1 \mathrm{~mol} \cdot \mathrm{L}^{-1}$ and the mole ratio of raw material for 1:13 roughly is the better choice.

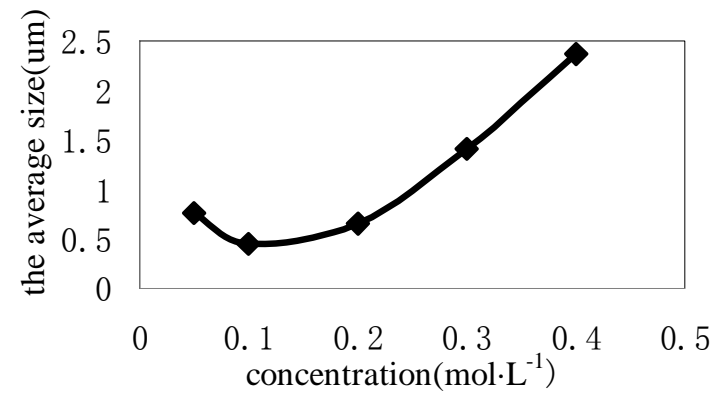

Fig.2.The influence of concentration of $\mathrm{Mg}\left(\mathrm{NO}_{3}\right)_{2}$ on $\mathrm{MH}$ average particle size

\section{Reaction time}

The influence of reaction time on the particle size of magnesium hydroxide was presented in Fig.3. Generally, the reaction between magnesium nitrate with ammonia solution is quickly. amorphous state of $\mathrm{MH}$ was formed in the reaction initial stage, and then transformed to crystal state after certain time, so if the reaction time is too short, the amorphous state of $\mathrm{MH}$ will easily reunion into big particles. With the extension of reaction time, the activity of MH increase, small magnesium hydroxide can separate itself from large $\mathrm{MH}$ particles and become the smaller products. However, the tiny magnesium hydroxide particles can occur secondary reunion with too much reaction time, which form larger particles. The average particle size of final products will increase instead. According to the result of the experiment, the reaction time for $0.5 \mathrm{~h}$ is better choice.

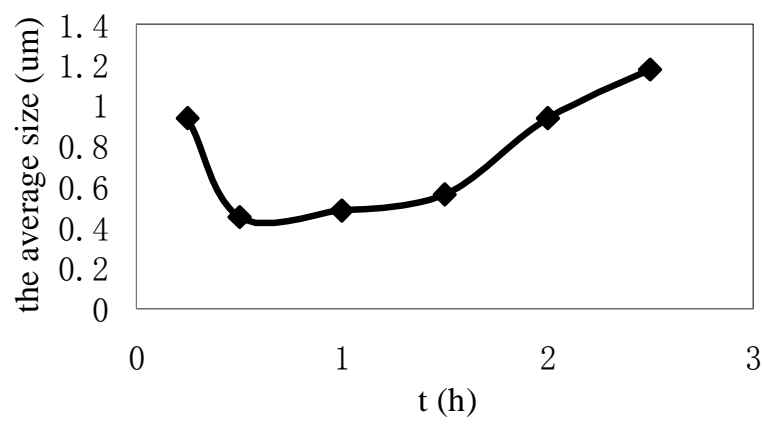

Fig.3.Tthe influence of reaction time on $\mathrm{MH}$ average particle size

\section{The additive}

The influence of the additive on the particle size of magnesium hydroxide were presented in Fig.4 and Fig. 5.

Fig. 4 implied that ethanol helps to reduce the reunion of super fine magnesium hydroxide, with the increase of the additive amount of ethanol, the dispersing ability of ethanol is more apparent. When the amount of ethanol is $90 \mathrm{~mL}-100 \mathrm{~mL}$, the average size of $\mathrm{MH}$ keep in a stable range, and because the adsorption quantity of the surface of $\mathrm{MH}$ reach saturated conditions, which can prevent particle reunion effectively. When the amount of ethanol for $100 \mathrm{ml}, \mathrm{D}(90)=208 \mathrm{~nm}$, the 
particle size of $\mathrm{MH}$ mainly distribute at range $120 \mathrm{~nm}$ to $150 \mathrm{~nm}$.

Fig.5 shows the test results of Laser particle size analyzer D (90) with different additive amount of PEG6000. PEG6000 is a kind of non-ion surfactants, it possesses low toxicity and environmental characteristics. Usually the ultrafine particles with large specific surface area are easily agglomerateed to big particles. The surfactant can reduce the free energy and stop the surface to gathere together, which restrain the growing up of $\mathrm{MH}$. When the additive amount of PEG6000 is less than $4 \%\left(\mathrm{PEG} 6000 \%=\mathrm{mPEG} 6000 / \mathrm{m} \mathrm{Mg}\left(\mathrm{NO}_{3}\right)_{2} \cdot 6 \mathrm{H}_{2} \mathrm{O}\right)$, PEG6000 is adsorbed or wrapped incompletely in $\mathrm{MH}$ surface, therefore PEG600 cannot well attain a space resistance function. When the additive amount of PEG6000 is more than $8 \%$, the average sizes of $\mathrm{MH}$ get big obviously. In this case, the adsorption quantity of particle surface close to saturation state, and the rest of free PEG6000 will associate with each other, which lead to a certain flocculation and reduce the stability of the system. So it can't form smaller magnesium hydroxide particles when the surfactant is excessive. The additive amount of PEG6000 for 6\% is the better choice. At this time, D (90) $=208 \mathrm{~nm}$, the particle size of $\mathrm{MH}$ mainly distribute at range $120 \mathrm{~nm}$ to $152 \mathrm{~nm}$.

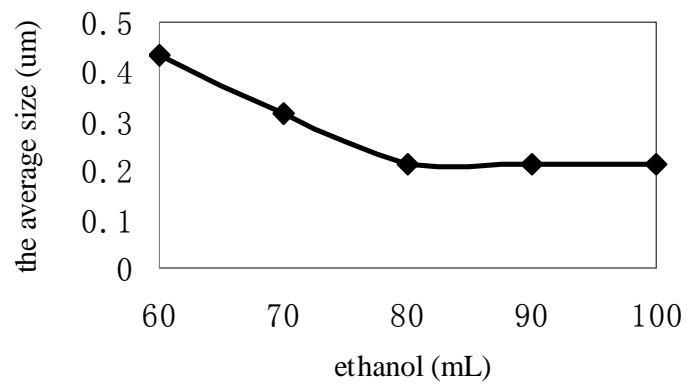

Fig.4. The influence of the amount of ethanol on MH average particle size

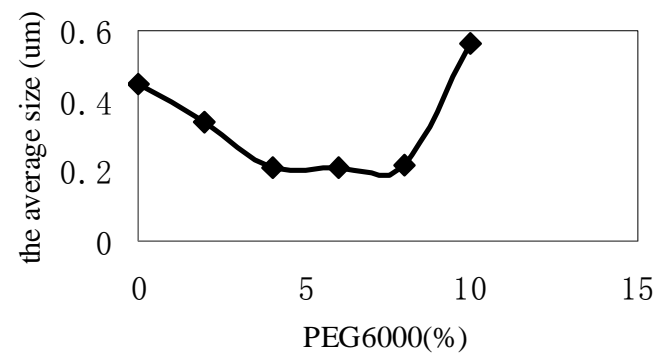

Fig.5. The influence of the amount of PEG6000 on MH average particle size

\section{E. XRD patterns of synthesized $\mathrm{Mg}(\mathrm{OH})_{2}$ samples.}

Fig. 6 shows the typical XRD patterns of the final products prepared by ethanol and PEG6000 as the dispersing agent. It is noted that the diffraction peaks are strong and sharp when ethanol or PEG6000 was used as the dispersing agent, and indicate that the crystallization of two kinds of samples is good.

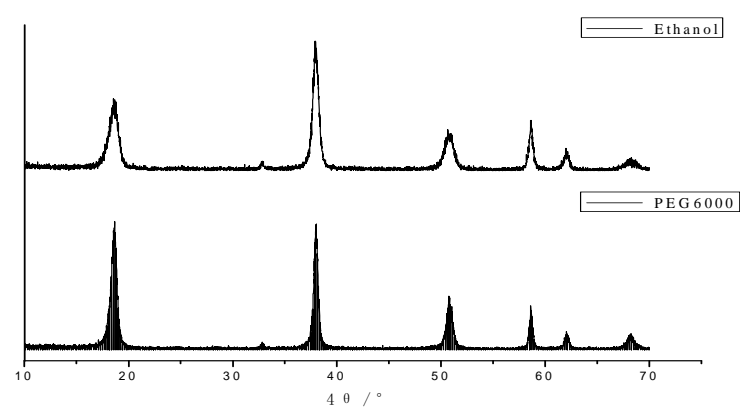

Fig.6. XRD patterns of samples

\section{CONCLUSIONS}

Super fine magnesium hydroxide is prepared with two kinds of dispersing agents by direct precipitation method, the optimal parameters: reaction temperature for $30{ }^{\circ} \mathrm{C}$, solution concentration for $0.1 \mathrm{~mol} \cdot \mathrm{L}^{-1}$, reaction time for $0.5 \mathrm{~h}$, the additive volume of ethanol for $100 \mathrm{~mL}$ or the additive amount of PEG6000 for 6\%. And the XRD patterns of the final products prepared with ethanol or PEG6000 as the dispersing agent shows that the crystallization of two kinds of samples is good. From the point of view of economic and environmental protection, super fine magnesium hydroxide is prepared with PEG6000 as the dispersing agents, which is the better method.

\section{REFERENCES}

[1] Qiu Long zhong, Xie Rong cai, Ding Peng, et al. Preparation and characterization of $\mathrm{Mg}(\mathrm{OH})_{2}$ nanoparticles and flame-retardant property of its nanocomposites with EVA [J]. Composite Structures, 2003, vol.62 (3/4), pp. 391-395

[2] Lv Jianping, Qiu Longzhen and Qu Baojun. Controlled growth of three morphological structures of magnesium hydroxide nanoparticles by wet precipitation method [J]. Journal of Crystal Growth, 2004, vol.267(3/4) ,pp.676-684.

[3] Rothon R N, Hornsby P R. Flame retardant effects of magnesium hydroxide [J]. Polym. Degdn. Stab, 1996, vol.54 ,pp. 383-385.

[4] Ding Yi, Zhang Guangtao, Wu Hao, et al. Nanoscale magnesium hydroxide and magnesium oxide powders: control over size, shape, and structure via hydrothermal synthesis[J] . Chem. Mater, 2001, vol.13 (2) ,pp. 435-440.

[5] Xiang Lan, Jin Yongcheng, Jin Yong. Hydrothermal formation of dispersive $\mathrm{Mg}(\mathrm{OH})_{2}$ particles in $\mathrm{NaOH}$ solution [J] . Trans. Nonferrous Met. Soc. China, 2004, vol.2 (14) ,pp.370-3756.

[6] Sun Yongming, Qian Yunhua, Xu Haiqing. Research on manufacturing of super fine magnesium hydroxide [J]. Applied Chemical Industry, 2009 , vol.38(2),pp. 264-266.

[7] ZhengYifan, Yue Linhai, JinDalai, et al.The Characteristic of $\mathrm{Mg}(\mathrm{OH})_{2}$ Crystallite in Hydrothermal Condition[J].Chinese Journal of inorganic Chemistry, 2003, vol.19( 6) ,pp.636-640.

[8] JingDiance. Preparation and Kinetics of Magnesium Oxide Nanorods [D].Dalian,Dalian university of technology, 2008.

[9] Yan C L, Xue D F. Preparation of magnesium hydroxide nanoflowers [J]. Joumal of Crystal Growth, 2005, vol.282,pp.448-454.

[10] BaiMei, LiuYouzhi, ShenHongyan. Research Progress on Preparation of Flame Retardant of Nano- $\mathrm{Mg}(\mathrm{OH})_{2}$ by Precipitation[ J].Plastics Science and Technology, 2011, vol.39(6) ,pp. 84-87. 